Tropical Journal of Pharmaceutical Research October 2019; 18 (10): 2031-2035

ISSN: $1596-5996$ (print); 1596-9827 (electronic)

(c) Pharmacotherapy Group, Faculty of Pharmacy, University of Benin, Benin City, 300001 Nigeria.

Available online at http://www.tjpr.org

Original Research Article

http://dx.doi.org/10.4314/tjpr.v18i10.5

\title{
Dexmedetomidine pretreatment alleviates ischemia- reperfusion injury-induced inflammatory reaction via inhibition of TLR-4/NF-KB signaling pathway
}

\author{
Haiping Zhang ${ }^{1}$, Zhiying $\mathrm{Wu}^{2}$, Nanhuo $\mathrm{Han}^{1}$, Lu Xü ${ }^{3}$ Kai Xiong ${ }^{1 *}$ \\ ${ }^{1}$ Department of Anesthesiology, ${ }^{2}$ Department of Radiotherapy, Nanchang 334 Hospital, No. 97, East 2nd Road, Xinxi Bridge, \\ Qingyunpu District, Nanchang City, Jiangxi Province 330024, ${ }^{3}$ Resuscitation Room, The Fourth Affiliated Hospital of Nanchang \\ University, Square South Road, Xihu District, Nanchang City, Jiangxi Province 330003, China
}

*For correspondence: Email: cnrj92@163.com

Sent for review: 17 July 2019

Revised accepted: 28 September 2019

\begin{abstract}
Purpose: To study the effect of dexmedetomidine on ischemia-reperfusion injury (IRI)-induced inflammatory response, as well as its underlying mechanism of action.

Methods: Three groups of healthy adult Sprague Dawley (SD) rats (mean weight, $275 \pm 10 \mathrm{~g}$ ): control, $I R I$ and treatment groups were used. With the exception of control group, ligation was performed on left anterior descending coronary arteries for $30 \mathrm{~min}$ and blood perfusion was restored within $100 \mathrm{~min}$ to establish IRI. Control group rats were without left ligation. Rats in control and IRI groups received normal saline intraperitoneally $30 \mathrm{~min}$ prior to surgery, while the treatment group received $100 \mu \mathrm{g} / \mathrm{kg}$ dexmedetomidine via intraperitoneal injection $30 \mathrm{~min}$ before operation. Infarct volume was determined using triphenyl tetrazolium chloride (TTC) staining. IL-6) and TNF-a levels of myocardial tissues and serum were determined using enzyme-linked immunosorbent assay (ELISA). Western blotting was used to determine protein expressions of NF-KB and TLR-4 in myocardial tissues.

Results: Pretreatment with dexmedetomidine markedly decreased infarct volume caused by $I R I(p<$ 0.05). Serum and myocardial TNF- $\alpha$ and IL-6 were significantly upregulated in IRI group, relative to control group, but were downregulated by pretreatment with dexmedetomidine $(p<0.05)$. There was marked upregulation of NF-KB and TLR-4 proteins in IRI rats, relative to untreated rats $(p<0.05)$. Dexmedetomidine also down-regulated the expressions of these proteins $(p<0.05)$.

Conclusion: Pretreatment with dexmedetomidine alleviates IRI-induced inflammatory reaction via suppression of TLR-4/NF-KB signaling pathway. This finding provides a basis for large-scale clinical trials with dexmedetomidine.
\end{abstract}

Keywords: Myocardial ischemia-reperfusion injury, Dexmedetomidine, Pretreatment, Inflammatory response

This is an Open Access article that uses a fund-ing model which does not charge readers or their institutions for access and distributed under the terms of the Creative Commons Attribution License (http://creativecommons.org/licenses/by/4.0) and the Budapest Open Access Initiative (http://www.budapestopenaccessinitiative.org/read), which permit unrestricted use, distribution, and reproduction in any medium, provided the original work is properly credited.

Tropical Journal of Pharmaceutical Research is indexed by Science Citation Index (SciSearch), Scopus, International Pharmaceutical Abstract, Chemical Abstracts, Embase, Index Copernicus, EBSCO, African Index Medicus, JournalSeek, Journal Citation Reports/Science Edition, Directory of Open Access Journals (DOAJ), African Journal Online, Bioline International, Open-J-Gate and Pharmacy Abstracts

\section{INTRODUCTION}

Cardiac ischemia is common among patients undergoing non-cardiac surgery. Blood perfusion of myocardial ischemic infarction site is immediately restored after surgery to avoid aggravating myocardial damage in the ischemic area. This phenomenon is called myocardial ischemia-reperfusion injury (MIRI) [1], and it is common in patients with heart disease 
undergoing either cardiac surgery, myocardial infarction thrombolysis or non-cardiac surgery. The precise molecular mechanism underlying the pathogenesis of MIRI remains unknown. However, calcium overload, oxygen free radicals, and activation of neutrophils have been postulated to play key roles [2]. In the 1980s, a concept of myocardial ischemic preconditioning was proposed, which is now the generally accepted mechanism for endogenous protection, but it is limited in clinical application, since it cannot provide explanation for the process of myocardial damage. This has prompted studies in search of drugs that can produce pre-adapted effects without organ damage [3,4].

Dexmedetomidine, an emerging selective a2 receptor agonist, is a widely used anesthetic [5]. Studies have shown that it maintains hemodynamic stability in patients with cardiovascular disease during the preoperative period. Dexmedetomidine reduces the levels of inflammatory factors and occurrence of myocardial ischemia in experimental animals, an indication that it plays an important role in alleviating IRI-induced myocardial inflammation [6]. However, there are controversies surrounding the protective mechanism of dexmedetomidine in MIRI [7]. Studies have shown that NF-kB and TLR-4 are closely related to inflammatory response in MIRI [8]. This study investigated the influence of dexmedetomidine on IRI-induced inflammatory response, and the underlying mechanism.

\section{EXPERIMENTAL}

\section{Materials}

Dexmedetomidine injection was purchased from Jiangsu Hengrui Medicinal Co. Ltd. Chloral hydrate. Mouse ventilator was obtained from Shanghai Alcott Biotechnology Co. Ltd. Triphenyltetrazole chloride (TTC). Evan blue dye was product of Sigma (USA), while ELISA kits were purchased from Shanghai Soleboard Co. Ltd. Anti-NF-kB and anti-TLR-4 antibodies were products of Beijing Zhongshan Jinqiao Co. Ltd. Phosphate-buffered saline (PBS) and centrifuge were purchased from Leica (Germany). This research received approval from Animal Ethics Committee of our institution (approval no. 0182183) and was conducted in line with the NIH regulations [9].

\section{Experimental rats and grouping}

Three groups of healthy adult SD rats (mean weight $=275 \pm 10 \mathrm{~g}$ ): control, $I R I$ and treatment groups were used (14/group). They were housed in metal cages under standard conditions of animal care, and were given standard feed and water ad libitum. They were kept under 12-h light/12 $\mathrm{h}$ photoperiod, and maintained at temperatures between $25{ }^{\circ} \mathrm{C}$, and relative humidity of $48-60 \%$. They were given routine disinfection and anesthesia with pentobarbital, and were connected to ECG and respiratory ventilator. With the exception of control group, the left-side anterior descending coronary arteries were ligated for $30 \mathrm{~min}$, and blood perfusion was restored within $100 \mathrm{~min}$ to establish IRI. The sham-operated group was without left ligation. Rats in the control and IRI sham-operated groups received normal saline intraperitoneally 30 min before surgery, while the treatment group received $100 \mu \mathrm{gg} / \mathrm{kg}$ bwt dexmedetomidine via intraperitoneal injection 30 min before operation.

\section{Myocardial infarct volume}

Myocardial infarct volume was measured using TTC staining method [10]. The cervical vein of each rat was rapidly injected and stained with 2 $\mathrm{ml}$ of $2 \%$ Evan blue dye, followed by heart excision. Myocardial tissues along the long axis of the left ventricle were immersed in TTC solution. Then, they were divided into blue (normal myocardial tissue), red (ischemic myocardial tissue), and pale (infarcted myocardial tissue). The volume of infarction areas was calculated using Image $\mathrm{J}$ software.

\section{Evaluation of tumor necrosis factor- $\alpha$ and interleukin-6 in serum}

Blood ( $3 \mathrm{ml}$ ) was drawn from the right jugular vein, subjected to centrifugation at $1,500 \mathrm{rpm}$, and the resultant serum was cryopreserved in Eppendorf tube. The respective ELISA kits were used for assay of TNF- $\alpha$ and IL-6.

\section{Determination of TNF- $\alpha$ and IL- 6 in myocardial tissues}

At the end of reperfusion, rat myocardial tissue was digested with trypsin and the resultant cell suspension was clarified through centrifugation at $4{ }^{\circ} \mathrm{C}$ at $8000 \mathrm{~g}$ for $0.5 \mathrm{~h}$. The supernatant was collected in a centrifuge tube, and the protein was denatured in a boiling water bath, and refrigerated. The amounts of the two cytokines in the supernatant were assayed with their respective kits.

\section{Western blotting}

Protein expressions of $\mathrm{NF}_{-\mathrm{K}} \mathrm{B}$ and TLR-4 in myocardial tissues were determined using 
Western blotting [11]. Cell suspension resulting from trypsinization of myocardial tissue was rinsed 2 times in PBS, and lysed with cold RIPA buffer tainted with protease inhibitor. The resultant lysate was centrifuged at $15,000 \mathrm{rpm}$ for $15 \mathrm{~min}$ at $4{ }^{\circ} \mathrm{C}$. The protein was quantified with BCA assay kit. A portion of total cell protein $(30 \mu \mathrm{g})$ was subjected to SDS-PAGE. The protein bands were then transferred to a fixed polyvinylidene fluoride membrane at $110 \mathrm{~V}$ and $90^{\circ} \mathrm{C}$ for $120 \mathrm{~min}$. Subsequently, non-fat milk (5 $\%)$ in TBS-T was added, with gentle shaking at $37{ }^{\circ} \mathrm{C}$, and incubated to block non-specific binding of the blot. Incubation of the blots was performed overnight at $4{ }^{\circ} \mathrm{C}$ with primary antibodies of rabbit polyclonal anti-NF-K $\mathrm{B}, \mathrm{TLR}-4$ and GAPDH at a dilution of 1 to 1000 , after which it was incubated with HRP-bound secondary antibody for $1.5 \mathrm{~h}$. The blot was developed using an X-ray film. Grayscale analysis of the bands was done with image $\mathrm{J}$ processing software. The respective protein expression levels were normalized to that of GAPDH standard.

\section{Statistical analysis}

The data are presented as mean \pm SEM, and were statistically analyzed with Statistical Package for the Social Sciences (18.0). Group comparison was done with $X^{2}$ test. Statistical significance was fixed at $p<0.05$.

\section{RESULTS}

\section{Myocardial infarct volume}

As presented in Table 1 and Figure 1, pretreatment with dexmedetomidine significantly reduced the infarct volume due to IRI $(p<0.05)$.

\section{TNF- $\alpha$ and IL-6 levels in myocardial tissue}

As shown in Table 2, there were marked upregulations of myocardial tissue TNF- $\alpha$ and IL6 in IRI rats, relative to control rats $(p<0.05)$. However, pretreatment with dexmedetomidine led to significant downregulation of these cytokines $(p<0.05)$.

Table 1: Myocardial infarct size $(n=14, \%)$

\begin{tabular}{ll}
\hline Group & $\begin{array}{l}\text { Myocardial } \\
\text { infarct size (\%) }\end{array}$ \\
\hline Control & $0.00 \pm 0.00$ \\
$I R I$ & $56.34 \pm 4.66$ \\
Treatment & $50.16 \pm 4.00$ \\
$T$ & 3.765 \\
$P$ & 0.001 \\
\hline$P<0.05$, relative to $I R I$ group
\end{tabular}

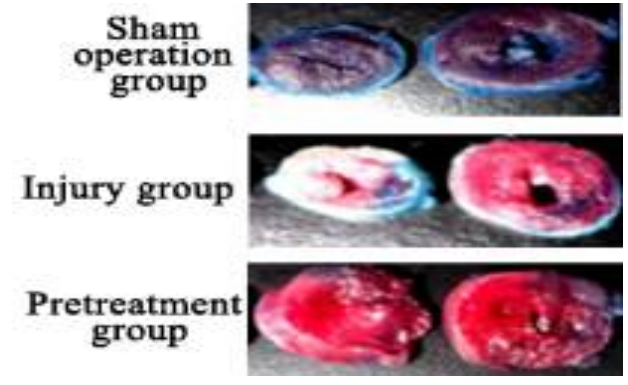

Figure 1: Myocardial tissue as revealed by TTC staining

Table 2: Myocardial levels of IL-6 and TNF- $\alpha$

\begin{tabular}{llll}
\hline Group & $\mathbf{N}$ & TNF- $\alpha(\mathbf{p g} / \mathbf{m L})$ & IL-6 $(\mathbf{p g} / \mathbf{m L})$ \\
\hline Control & 14 & $174.96 \pm 22.58$ & $130.44 \pm 16.49$ \\
IRI & 14 & $610.34 \pm 22.59$ & $340.29 \pm 17.44$ \\
Treatment & 14 & $280.36 \pm 25.38^{\#}$ & $206.25 \pm 12.43^{\#}$ \\
\hline$P<0.05$, vs untreated rats; ${ }^{\#} p<0.05$, vs IRI rats
\end{tabular}

\section{Serum levels of TNF- $\alpha$ and IL- 6}

Serum TNF- $\alpha$ and IL-6 were markedly upregulated in IRI rats, relative to control rats, but were markedly downregulated by pretreatment with dexmedetomidine $(p<0.05)$.

Table 3: Effect of dexmedetomidine on TNF- $\alpha$ and IL6 concentrations

\begin{tabular}{llll}
\hline Group & $\mathbf{n}$ & $\begin{array}{l}\text { TNF- } \boldsymbol{\alpha}(\mathbf{p g} / \mathbf{m L} \\
\text { IL-6 }(\mathbf{p g} / \mathbf{m L})\end{array}$ \\
\hline Control & 14 & $159.99 \pm 18.52$ & $100.41 \pm 16.37$ \\
IRI & 14 & $622.37 \pm 22.53$ & $340.13 \pm 29.28$ \\
Treatment & 14 & $241.34 \pm 10.18^{\#}$ & $161.22 \pm 12.09^{\#}$ \\
\hline \multicolumn{4}{l}{$P<0.05$, vs untreated rats, ${ }^{\#} p<0.05$, vs $I R I$ rats }
\end{tabular}

\section{Expressions of $\mathrm{NF}_{-\mathrm{K}} \mathrm{B}$ and TLR-4 proteins in myocardial tissue}

There were upregulated expressions of $\mathrm{NF}_{-\mathrm{K}} \mathrm{B}$ and TLR-4 proteins in IRI rats, relative to control rats $(p<0.05)$. Prior treatment with dexmedetomidine down-regulated the expressions of these proteins $(p<0.05$; Figure 2).

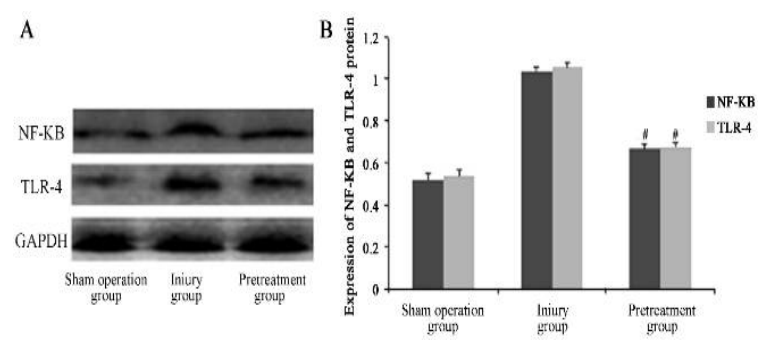

Figure 2. Effect of dexmedetomidine on $\mathrm{NF}_{-\mathrm{K}} \mathrm{B}$ and TLR-4. ${ }^{*} P<0.05$, vs untreated rats, ${ }^{\#} p<0.05$, vs $I R I$ group 


\section{DISCUSSION}

Cardiopulmonary resuscitation, organ transplantation, thrombolysis and bypass reperfuse ischemic tissues or organs with blood after surgery, in an attempt to repair damaged structures. However, in some organs with high oxygen demand such as brain and heart, reperfusion after ischemia may aggravate structural damage and dysfunction, and even lead to irreversible damage of tissues or organs. Myocardial necrosis is the most serious consequence of reperfusion after ischemia.

Dexmedetomidine, a highly selective $\alpha 2$ receptor agonist, has high affinity for a2 adrenergic receptor. In addition to its sedative, analgesic and antispasmodic effects, it inhibits the release of catecholamines, reduces sympathetic nerve function, and maintains hemodynamic stability without causing respiratory depression [12]. Pretreatment with dexmedetomidine has been shown to confer protection on MIRI [13].

In this study, the myocardial infarct volume of the treatment group was significantly reduced, when compared with that of $I R I$ group. This is in agreement with previous reports, an indication that pretreatment with dexmedetomidine may alleviate MIRI. Studies have shown that IRI is a congenital immune response in which the complement system erroneously attacks own tissue antigen [14]. Ischemic myocardial reperfusion is characterized by the release of high amounts of inflammatory factors and overactivation of the inflammatory response in which TNF- $\alpha$ has a major role, which not only directly damages myocardial cells, but also causes the release of large amounts of inflammatory factors. On the one hand, this causes micro-arterial spasm, thereby aggravating damaged tissue ischemia, and on the other hand, increases vascular permeability, thereby exacerbating inflammatory cell infiltration and tissue edema [15]. Interleukin-6 (IL-6) plays a pivotal role in inflammatory response. It has been suggested that IL-6 overexpression occurs in areas where inflammatory cells accumulate, leading to increase in complications after myocardial damage. This is an index which reflects body stress and severity of tissue cell damage [16]. Therefore, suppression of the synthesis and liberation of TNF- $\alpha$ and IL- 6 is key in reducing inflammation and MIRI.

The results of this study showed that myocardial and blood TNF- $\alpha$ and IL- 6 concentrations were markedly increased in IRI group, when compared with untreated rats, but were significantly reduced by pretreatment with dexmedetomidine.
These results suggest that large amounts of inflammatory factors may be released during IRI, and that dexmedetomidine may lower inflammatory reaction induced by TNF- $\alpha$ and IL6.

The TLR-4/NF-K $B$ signaling route has been shown to be involved in the pathogenesis of IRI [17]. Toll-like receptors are expressed in immune cells and cardiomyocytes, and activate the innate immune response [18]. Toll-like receptor-4 (TLR4) activates downstream signal transduction pathways by specifically binding pathogenassociated molecular mode, thereby performing a vital function in the onset of inflammationrelated responses. The transcription factor NF${ }_{k} \mathrm{Ba}$, a major regulator of responses associated with the immune system and inflammation, is ubiquitously expressed in eukaryotic cells. Tolllike receptor-4 (TLR-4) activates NF-kB after interaction with pathogen-associated molecular signals, which in turn induce downstream signal transduction and promote the initiation of inflammatory responses [19]. Studies have shown that ischemia-reperfusion rapidly activates myocardial transcription factor $\mathrm{NF}_{-k} \mathrm{~B}$, blocks its expression and shrinks the area of myocardial infarction in rats. Over-activation of $\mathrm{NF}_{-\mathrm{K}} \mathrm{B}$ is responsible for the death of myocardial cells after ischemia-reperfusion. It has been suggested that blockage of TLR-4/NF- ${ }_{-K} B$ signal route may be an important target for the treatment of IRI [20]. In this study, the protein expressions of $\mathrm{NF}_{-\mathrm{K}} \mathrm{B}$ and TLR-4 in myocardial tissue were significantly upregulated in IRI group, an indication that reperfusion injury after ischemia may be accompanied by over-activation of the TLR-4/NF${ }_{k} B$ signal route. It is likely that dexmedetomidine inhibits the TLR-4/NF-k $\mathrm{B}$ signal route.

\section{CONCLUSION}

Pretreatment with dexmedetomidine alleviates IRI-induced inflammatory reaction via suppression of TLR-4/NF-K $B$ signal route. This finding provides a basis for large-scale clinical trials with dexmedetomidine.

\section{DECLARATIONS}

\section{Conflict of interest}

No conflict of interest is associated with this work.

\section{Contribution of authors}

This work was done by the authors named in this article, and the authors accept all liabilities 
resulting from claims which relate to this article and its contents. Kai Xiong designed the study and interpreted the results. Haiping Zhang, Zhiying Wu, Nanhuo Han, Lu Xu, Kai Xiong collected data and drafted the manuscript. Haiping Zhang performed the experiments.

\section{Open Access}

This is an Open Access article that uses a funding model which does not charge readers or their institutions for access and distributed under the terms of the Creative Commons Attribution License (http://creativecommons.org/licenses/by/ 4.0) and the Budapest Open Access Initiative (http://www.budapestopenaccessinitiative.org/rea d), which permit unrestricted use, distribution, and reproduction in any medium, provided the original work is properly credited.

\section{REFERENCES}

1. Wu $X Y$, Miao L, Zheng $R$, Fan GW. Progress in myocardial ischemia-reperfusion injury. Chin J Clin Pharm 2016; 32(11): 1043-1045.

2. Qiao Y, Meng ZH, Guo LJ, Li ZJ. Mechanisms and treatment of myocardial ischemia-reperfusion injury. Basic Med Clin 2015; 35(12): 1666-1671.

3. Ye M, Wu H. New advances in myocardial ischemiareperfusion injury. Chin J Senile Cardiovasc Dis 2016; 18(4): 434-437.

4. Yu H, Cao H, Wang Q, Zhang Y, Chen MH, Feng J, Yang $Z Y$. Study on the effect of myocardial ischemic preconditioning on thrombolytic therapy in patients with acute myocardial infarction. Chin Gen Med 2015; 13(12): 1918-1920.

5. Hu M, Miao D, Liu R, Choi YS. Effects of dexmedetomidine on stress response in patients undergoing spinal anesthesia surgery. $J$ Clin Anesthesiol 2015; 23(1): 45-46.

6. Chen $X$, Chen $G$. Effects of dexmedetomidine on hemodynamics and brain protection in patients undergoing intracranial tumor surgery. J Clin Anesthesiol 2015; 31: 15-17.

7. Kou D, Wang Z, Bian W, Han JG. Effects of dexmedetomidine on myocardial injury in patients undergoing off-pump coronary artery bypass grafting. China Continuing Med Educ 2015; 31(1): 75-76.

8. Jin X, Wu Yi, Fan CH, Zhu PA. Clinical characteristics of children with positive detection of respiratory syncytial virus nucleic acid. China New Clin Med 2018; 11(24): 758-762.
9. World Health Organization. Principles of laboratory animal care. WHO Chron 1985; 39: 51-56.

10. Li M, Wang J, Xu F, Yuan QH, Liu BS, Pang XX, Zhang $Y$, Chen $Y G$. Acute hyperglycemia aggravates myocardial ischemia/reperfusion injury in rats by inhibiting ALDH2 activity. J Shandong Univ 2015; 53(4): 15-20.

11. Wang SX, Pu J, Liu CQ, Li C, Yan ZH Cui LH. Expression and clinical significance of inflammatory factors TNF-alpha, IL-6 and IL-4 in ulcerative colitis. J Gastroenterol Hepatol 2015; 1(1): 104-106.

12. He $Q, Q u Y$. The effect of dexmedetomidine anesthesia on the operation condition, RAAS activity and renal function of patients undergoing open surgery. Chin $J$ Biochem Drugs 2016; 36(6): 103-105.

13. Fu W, Gu EW, Wang $H$, Mei M, Chen QS, Zhao $H$. Effects of different doses of dexmedetomidine on myocardial injury in patients undergoing cardiopulmonary bypass revascularization. Chongqing Med College 2015; 1(4): 492-494.

14. Wu ZL, Chu SJ, Yao SL, Wu J. Effects of different doses of dexmedetomidine preconditioning on myocardial ischemia-reperfusion injury and inflammatory response in rats. J Huazhong Univ Sci Technol 2015; 1(4): 445447.

15. Spanaus KS, Schlapbach R, Fontana A. TNF- $\alpha$ and IFN$V$ render microglia sensitive to Fas ligand-induced apoptosis by induction of Fas expression and downregulation of Bcl-2 and Bcl-xL. Eur J Immunol 2015; 28(12):4398-4408.

16. Eugster HP, Frei K, Kopf M, Lassmann H, Fontana A. IL6-deficient mice resist myelin oligodendrocyte glycoprotein-induced autoimmune encephalomyelitis. Eur J Immunol 2015; 28(7): 2178 - 2187.

17. Xing QM, Lu S, Zhou YH, Li Lan, Zhou CG, Shen LJ. Intervention of Shengmai Powder on DCM rats and its effect on TLR-4/NF-kappa B inflammatory signaling pathway. Chin J Exp Formulas 2018; 2(1): 128-134.

18. Kumar $P$, Gogulamudi VR, Periasamy R, Raghavaraju G, Subramanian $U$, Pandey $K N$. Inhibition of HDAC enhances STAT acetylation, blocks NF-KB, and suppresses the renal inflammation and fibrosis in Npr1 haplotype male mice. Am J Physiol Renal Physiol 2017; 313: 781-795.

19. Sp N, Kang DY, Kim DH, Park JH, Lee HG, Kim HJ, Darvin P, Park YM, Yang YM. Nobiletin Inhibits CD36Dependent Tumor Angiogenesis, Migration, Invasion, and Sphere Formation Through the Cd36/Stat3/Nf-Kb Signaling Axis. Nutrients 2018; 10(6): 772-776.

20. Yu Y, Yu Y, Liu M, Yu P, Liu G, Liu Y, Su Y, Jiang $H$, Chen $R$. hyl pyruvate attenuated coxsackievirus B3induced acute viral myocarditis by suppression of HMGB1/RAGE/NF-KB pathway. Springerplus 2016; 5(1): 1-10. 